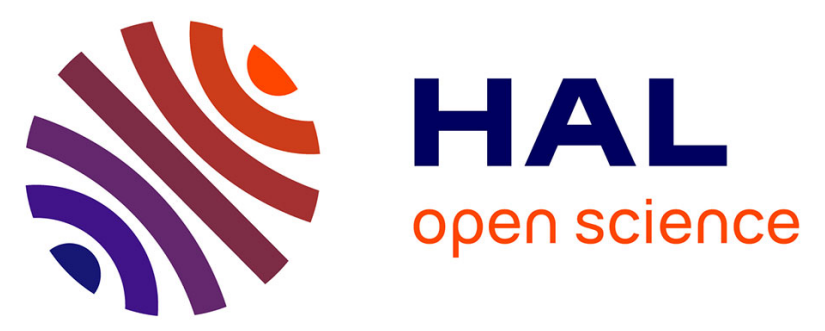

\title{
Micron-sized PFOB liquid core droplets stabilized with tailored-made perfluorinated surfactants as a new class of endovascular sono-sensitizers for focused ultrasound thermotherapy
}

Stéphane Desgranges, Orane Lorton, Laura Gui-Levy, Pauline Guillemin, Zarko Celicanin, Jean-Noël Hyacinthe, Romain Breguet, Lindsey Crowe, Christoph Becker, Marine Soulie, et al.

\section{- To cite this version:}

Stéphane Desgranges, Orane Lorton, Laura Gui-Levy, Pauline Guillemin, Zarko Celicanin, et al.. Micron-sized PFOB liquid core droplets stabilized with tailored-made perfluorinated surfactants as a new class of endovascular sono-sensitizers for focused ultrasound thermotherapy. Journal of materials chemistry B, 2019, 7 (6), pp.927-939. 10.1039/C8TB01491D . hal-02187990

\section{HAL Id: hal-02187990 \\ https://hal.sorbonne-universite.fr/hal-02187990}

Submitted on 18 Jul 2019

HAL is a multi-disciplinary open access archive for the deposit and dissemination of scientific research documents, whether they are published or not. The documents may come from teaching and research institutions in France or abroad, or from public or private research centers.
L'archive ouverte pluridisciplinaire HAL, est destinée au dépôt et à la diffusion de documents scientifiques de niveau recherche, publiés ou non, émanant des établissements d'enseignement et de recherche français ou étrangers, des laboratoires publics ou privés. 
$1 \quad$ Micron-sized PFOB liquid core droplets stabilized with tailored-made perfluorinated surfactants as a new class of endovascular sono-sensitizers

6 Stéphane Desgranges*, ${ }^{1,2}$ Orane Lorton, ${ }^{1}$ Laura Gui-Levy, ${ }^{1}$ Pauline Guillemin, ${ }^{1}$ Zarko

7 Celicanin, ${ }^{3}$ Jean-Noel Hyacinthe, ${ }^{1,4}$ Romain Breguet, ${ }^{1}$ Lindsey A. Crowe, ${ }^{1}$ Christoph D.

8 Becker, ${ }^{5}$ Marine Soulié, ${ }^{2}$ Nicolas Taulier, ${ }^{6}$ Christiane Contino-Pépin, ${ }^{2}$ Rares Salomir ${ }^{1,5}$

9 (1) Image Guided Interventions Laboratory, Faculty of Medicine, Radiology Department, Geneva, Switzerland

(2) Equipe Chimie Bioorganique et Systèmes Amphiphiles, Institut des Biomolécules Max Mousseron, UMR 5247, Université d'Avignon et des Pays de Vaucluse, 84911 Avignon, 13 France,

(3) Radiological Physics, University of Basel, Switzerland

(4) School of Health Sciences, HES-SO // University of Applied Sciences and Arts of

Western Switzerland, Geneva, Switzerland

(5) University Hospitals of Geneva, Radiology Department, Geneva, Switzerland

(6) Sorbonne Université, CNRS, INSERM, Laboratoire d'Imagerie Biomédicale, LIB, F75006 Paris, France.

*Corresponding author 


\section{Abstract}

The purpose of this study was to develop micron-sized droplet emulsions able to increase the heat deposition of high intensity focused ultrasound (HIFU), aiming to accelerate the tumour ablation in highly perfused organs with reduced side effects. The investigated droplets consisted of a perfluorooctyl bromide (PFOB) core coated with a biocompatible fluorinated surfactant called F-TAC. The novelty of this work relies on the use, for this application, of a high boiling point perfluorocarbon core $\left(142^{\circ} \mathrm{C}\right)$, combined with an in-house fluorinated surfactant to formulate the emulsion, yielding quasi-reversible strong interactions between the HIFU beam and the droplets. In order to fine-tune the emulsion size, surfactants with different hydrophobic/hydrophilic ratios were screened. Different concentrations of PFOB droplets were homogeneously embedded in two different MRI compatible tissue mimicking materials (TMM), exhibiting either ultrasound (US) absorbing or non-absorbing properties. For the US absorbing TMM, the speed of sound at each droplet concentration was also assessed. These TMM were sonicated by $1 \mathrm{MHz}$ HIFU with acoustical power of $94 \mathrm{~W}$ at two different duty cycles. The temperature elevation was monitored accurately by MRI proton shift resonance frequency in near real-time. The presence of sono-sensitive droplets induced a significant increase of the HIFU thermal effect that persisted under repeated sonication of the same locus. Optimal enhancement was observed at the lowest concentration tested $(0.1 \%)$ with an additional temperature rise at the focal point of approximately $4{ }^{\circ} \mathrm{C}$ per applied $\mathrm{kJ}$ of acoustic energy corresponding to one order of magnitude augmentation of the thermal dose. Furthermore, no deformation of the heating pattern pre- or post-focal was observed. 


\section{Introduction}

High intensity focused ultrasound (HIFU) is a promising non-invasive and non-ionizing treatment for ablation of solid tumours. ${ }^{1,2}$ It has FDA approval for the treatment of uterine fibrosis $^{3}$, and is in clinical development to treat several solid malignant tumours including liver, prostate, breast, bladder, kidney and soft tissue sarcoma. ${ }^{4-10}$ However, it possesses several shortcomings such as long treatment duration to fully ablate the tumour ${ }^{1,11}$ and, for deep-seated tumours, high ultrasound (US) intensity is required leading to an increase in side effects. In addition, even when US energy is concentrated to the focal point, it can also be deposited along the US beam in front or behind the focus point and cause severe side effects such as skin and bone burning. ${ }^{8,12-14}$ Furthermore, given a treatment planning, interpatient variation in the volume and shape of the lesion may be difficult to control and to reproduce. $^{15}$

The ablative effects of HIFU are due to the focusing of high energy beams in a small region on the order of the wavelength, i.e. on the millimetre scale. ${ }^{1}$ At the focal spot, the temperature can rise by 15 to $50{ }^{\circ} \mathrm{C}$ within seconds, resulting in a rapid blood coagulation and inducing cell necrosis. The damage to the tumours involves two synergistic phenomena. The first is the thermal deposition of energy and is proportional to the coefficient of absorption of the tissue. The second is the inertial cavitation (IC) ${ }^{1}$ yielding mechanical damages to cell structure and that can also increase the thermal effect consecutive to the emission of acoustic waves at higher frequency than the incident beam, that is, mode conversion phenomenon. ${ }^{16}$

Several approaches have been investigated to amplify the thermal delivery during HIFU and hence to decrease the occurrence of side effects. The first approach was to use microbubbles (MB) filled with perfluorocarbon (PFC) gas that were originally used for ultrasound contrast enhancement. ${ }^{11,17,18}$ The MB serve as nuclei for inertial cavitation (IC) and act as enhancers of tissue heating rate as they absorb energy from the sound wave when they oscillate. ${ }^{16,19}$ However, as they are ultra-sensitive to US with a very low IC pressure threshold, they may cause unwanted damage along the US beam due to vaporisation of bubbles and/or initiation of IC, producing unwanted side effects such as uncontrollable pre-focal lesion and skin burn. ${ }^{11,19}$ Additionally, they exhibit a limited 
circulation half-life as gases diffuse rapidly in tissue. To overcome this limitation, an alternative approach would be to produce bubbles in-situ without an exogenous agent, however this method it is not satisfactory because of the high IC threshold of tissues, and the results can be highly variable due to the natural heterogeneity of tissues. ${ }^{20}$

The use of acoustic droplet vaporisation (ADV) was suggested to be more advantageous to the same purpose. The concept of ADV consists of using phase shift droplets (PSD) filled with a liquid PFC that undergoes a phase change from liquid to gas under the induction of an US wave. ${ }^{21,22}$ PFC droplets are able to vaporise, like any volatile liquid, provided a sufficient decrease in pressure below their vapour pressure or an increase in temperature above their boiling point. Under HIFU conditions, at the focal point, the negative pressure peak is sufficient to vaporise droplets into bubbles with a volumetric expansion at least 5 to 6 times the parent droplets. The resulting bubbles can be spatiotemporally controlled ${ }^{23,24}$ and, conversely to their unexcited liquid counterpart, possess better echogenic properties. The acoustic negative peak pressure necessary for this vaporisation depends on several factors, such the nature of PFC core, the type of shell and droplet size. These exogeneous droplets that provide bubbles in-situ act as nuclei for in vivo cavitation leading to tissue heating and lesion. ${ }^{25,26}$ Moreover, the formation of a bubble cloud would mostly reflect the incident ultrasonic beam and thus protect the far field tissues from US wave effect. ${ }^{27,28}$ The backward reflected wave would also contribute to an increase in the pressure amplitude in front of the bubble cloud and hence help further vaporisation. ${ }^{22}$

Like microbubbles, droplets are usually constituted of two parts: the core which contains at least one type of PFC and the shell made of a pure surfactant or a mixture of surfactants. For a given droplet composition, the size is an important feature for its vaporisation threshold, as a consequence of the Laplace pressure inside the droplet which is inversely proportional to its radius and to the interfacial pressure between the two liquids. Therefore, ADV requires more energy than the theoretical condition when a droplet was in contact with air. The larger the droplet, the lower the energy required to vaporise it. ${ }^{24,29}$ The choice of PFC core is a key factor. Several groups ${ }^{30,31}$ have developed superheated PFC filled droplets, which consist of a PFC with low boiling temperature, usually below human body temperature, that remains in liquid state at $37{ }^{\circ} \mathrm{C}$ thanks to either the Laplace pressure and interfacial tension or the metastability of the superheated liquid PFC against homogeneous nucleation. $^{32}$ 
This allows a decrease in the energetic vaporisation threshold and even the use of diagnostic US apparatus for this purpose. Droplets have another major advantage as they possess a longer circulation half-life than their gaseous homologues. ${ }^{22}$

There are two kinds of PSD. The first are PFC nanodroplets constituting nanoemulsions, called phase shift nanoemulsions (PSNE). Taking advantage of the enhanced permeability retention (EPR) effect, they can extravasate from the neovasculature and accumulate in the tumour microenvironment. These PSNE are used for imaging and/or therapy. $^{33-35}$ The second are micron-sized droplets (MSD) which are restrained to the vasculature (endo-vascular). They can be used for enhancing thermal ablation in highly perfused tumours ${ }^{15,36}$ and as well for embolotherapy as they generate micro-bubbles able to occlude small capillary vessels. ${ }^{23,37}$

In order to reduce the potential side effects ascribed to HIFU therapy when adapting it to highly perfused tumours, we report the use of perfluorooctylbromide (PFOB)-filled MSD to reduce the ultrasound exposure time and energy required for tumour ablation. Conversely to other reported studies, we used a PFC with a high boiling point $\left(142{ }^{\circ} \mathrm{C}\right)$ in order to gain in droplet stability ${ }^{26}$ and allowing a reverse phase shift once the HIFU beam is stopped, in order to avoid cellular and tissue damage as well as blood vessel occlusion. ${ }^{21}$ In other terms, high boiling point PFC droplets undergo quasi-reversible interactions with the HIFU beam, which subsequently avoids possible capillary occlusion due to volume expansion, permits recirculation of droplets in the blood stream after exposure to the HIFU and enables accurate spatial control of the thermal effects localized around the focal point. PFOB, a FDA approved PFC was used as a potential blood substitute because of its oxygen high solubilising ability, inertness and stability. ${ }^{38,39}$ It was shown that a formulation of PFOB with lecithin possesses a very low toxicity with a $\mathrm{LD}_{50}$ in rats of $45 \mathrm{~g} / \mathrm{kg}$ and a short half-life in the body of about 4 days for $2.5 \mathrm{~g} / \mathrm{kg}$ administrated. ${ }^{40}$

PFC droplets need to be stabilised with amphiphilic molecules such as lipids or fluorinated surfactants. ${ }^{41}$ The present study uses in-house surfactants called F-TAC which consist of a fluorinated hydrophobic moiety exhibiting a high affinity for PFC droplets and a hydrophilic moiety made of a polyTRIS oligomer ${ }^{42}$ (See Figure 1a). Contrary to commercially available fluorinated surfactants often used in the literature, such as ZONYL (Dupont De Nemours) and CAPSTONE (Chemours), F-TAC surfactants exhibit a good biocompatibility (no 
137 hemolytic activity, $\mathrm{LD}_{50}$ up to $4.5 \mathrm{~g} / \mathrm{kg}$ in rats after i.v. administration), have a ubiquitous 138 distribution in rat after i.v. or per os route, and display a long half-life (30-50h) without any 139 degradation in both plasma and tissues. ${ }^{43,44}$

The main goal of the study is the enhancement of HIFU mediated heat deposition by MSD embedded in tissue mimicking material. The influence of the F-TAC chemical structure 143 modification on droplet size and the impact of MSD concentration on the enhancement of HIFU thermal effect was assessed. To do so, the droplets were embedded either in an acoustically absorbent agar-based TMM that mimics the acoustic properties of soft tissue, ${ }^{45}$ or in a non-absorbent material made of gelatine gel to gain a better understanding of the mechanism of action of MSD. The velocity of sound in the used gel was assessed, as that gel preparation underwent some substantive change to be compatible with magnetic resonance (MR) imaging and guidance of the HIFU sonication. Given that the depth of US penetration is inversely proportional to the frequency, a $1 \mathrm{MHz}$ frequency used for HIFU sonification was considered to be a good compromise for deep tissue application, for instance in the liver or kidney. The temperature rise was monitored accurately throughout the gel by proton resonance shift frequency (PRSF) MR thermometry, and a diagnostic ultrasound device was used to investigate the attenuation of the backscattered signal from MSD doped gels. 


\section{Experimental (material and methods)}

2.1. Material

Agar, $\mathrm{SiO}_{2}(1.5$ and $0.5 \mu \mathrm{m}), \mathrm{Al}_{2} \mathrm{O}_{3}(3$ and $0.3 \mu \mathrm{m})$ were purchased from AlfaAeser (Karlsruhe, Germany), glycerol from Acros and Benzalkonium chloride (BAL) from Sigma-Aldrich (St. Quentin Fallavier, France), PFOB from Fluorochem (Hadfiel, United Kingdom), $1 \mathrm{H}, 1 \mathrm{H}, 2 \mathrm{H}, 2 \mathrm{H}-$ perfluorooctanethiol was graciously provided by Atomchem (Colombes, France), and all other reagents (sodium trifluoroacetate, AIBN) and solvents were of reagent grade.

\subsection{Surfactant synthesis}

In order to fine-tune the MSD size and to understand the surfactant chemical structure vs droplet size relationship, several in-house surfactants called F-TAC were screened. F-TAC are constituted of a non-ionic polar head comprising of $n$ repeating Tris(hydroxymethyl)aminomethane $\left(T_{A C}\right)$ units $(n=D P n$ is the average degree of polymerization) and of a hydrophobic perfluorinated tail $\left(\mathrm{F}_{6}=\mathrm{C}_{6} \mathrm{~F}_{13} \mathrm{C}_{2} \mathrm{H}_{4}\right.$ or $\left.\mathrm{F}_{8}=\mathrm{C}_{8} \mathrm{~F}_{17} \mathrm{C}_{2} \mathrm{H}_{4}\right)(\mathrm{See}$ Figure 1a).

Due to the fluorine-fluorine interaction, the fluorinated part of these amphiphilic molecules exhibits a high affinity for the perfluorocarbon core of the droplets while their polar head ensures the whole water solubility. ${ }^{43}$ Their synthesis previously described by Pucci et al. ${ }^{46}$ was easily performed in one step by free radical polymerisation, allowing a swift supply of surfactant of high quantity. For a given perfluorocarbon core, the size of the resulting MSD is on one hand correlated to the concentration and chemical structure of the surfactant and, on the other hand, to the level of energy delivered to the solution during the emulsification process. ${ }^{42,47}$ The chemical composition of the liquid core, the surfactant concentration and the process conditions were kept constant and only the impact of the surfactant chemical structure was assessed. Two different series were studied, each one being characterised by the length of its hydrophobic tail. The first one is the $F_{6}$ series with $F_{6}=C_{6} F_{13} C_{2} H_{4}$, while the second one is the $\mathrm{F}_{8}$ series with $\mathrm{F}_{8}=\mathrm{C}_{8} \mathrm{~F}_{17} \mathrm{C}_{2} \mathrm{H}_{4}$. Three different polar head sizes were tested for each series, with a respective DPn of 7, 12, 29 for the first series and 7, 13, 18 for the second series.

All surfactants were easily synthesised by free radical polymerisation in one step using two different perfluoroalkanethiols $\mathrm{C}_{6} \mathrm{~F}_{13} \mathrm{C}_{2} \mathrm{H}_{4} \mathrm{SH}$ or $\mathrm{C}_{8} \mathrm{~F}_{17} \mathrm{C}_{2} \mathrm{H}_{4} \mathrm{SH}$ as transfer reagents (telogen) and azobisisobutyronitrile (AIBN) as a radical initiator. Ten $\mathrm{ml}$ of solvent were used 
per gram of tris(hydroxymethyl) acrylamidomethane (THAM) $(\mathrm{C}=0.57 \mathrm{~mol} / \mathrm{L})$ and the concentration of AIBN was 0.5 eq of telogen. $R_{0}$ is the telogen/monomer molar ratio. The summary of the different polymerisation conditions is listed in Table 1.

Briefly, in a shlenck tube, dry methanol or a mixture of methanol and water (9/1) for the highest DPn, AIBN, THAM and telogen agent were added, the mixture underwent three cycles of freeze, vacuum, thaw and then was heated at $90^{\circ} \mathrm{C}$ for 4 hours under vigorous stirring until complete disappearance of the monomer. Then the crude product was precipitated twice in diethyl ether and filtrated and dried to recover the expected compound as a white powder with yields ranging from $31.8 \%$ to $84.0 \%$ (see Table 1 ). The DPn was assessed by ${ }^{19}$ F-NMR as described previously. ${ }^{42}$

\subsection{MSD preparation}

For our therapeutic purpose, the maximum droplet size in terms of vascular circulation is 6 $\mu \mathrm{m}$, given the strong requirement to avoid capillary blockage and to allow them to be transpulmonary. ${ }^{21}$ In preliminary studies (data no shown) we noticed that employing a high energy process using an ultrasonic device (Bioblock Scientific Vibracell 75043, 13-mm diameter sonotrode) always led to a bimodal population, one in a the nanometric range and one in the micrometric range. Accordingly, the emulsion was prepared using a low energy process using a homogeniser as with a Polytron ${ }^{\circledR}$ system PT 3100 homogenizer from Kinematica (Luzern Switzerland). General procedure: To prepare a 10\% volume fraction emulsion, $835 \mathrm{mg}$ of surfactant were dissolved in $58.5 \mathrm{ml}$ of water then $6.5 \mathrm{ml}$ of PFOB were added. The resulting mixture was cooled down with an ice bath and then the resulting emulsion was homogenised three times $15 \mathrm{~min}$ at $22500 \mathrm{rpm}$. Finally, the emulsion was kept at $4^{\circ} \mathrm{C}$ until use.

\subsection{Gel preparation}

As a proof of concept for the enhancement of HIFU-induced heat deposition by MSD and accurate MR thermometry, MSD were embedded into a tissue mimicking material (TMM). There are numerous TMM available, among them the most common are agar, urethane rubber, zerdine, silicone polyvinyl alcohol, polyacrylamide and gelatine. ${ }^{48-50}$ We decided to use the well characterised agar-based gel as it possesses several advantages such as having a sound velocity value close to that of soft tissue, it exhibits almost a linear response of 
attenuation to frequency and it can be stored for several weeks. ${ }^{45}$ Furthermore, this TMM possesses a high melting point of about $80^{\circ} \mathrm{C}$ and is reusable compared to other gels such as BSA-loaded polyacrylamide. ${ }^{51}$

222

\subsubsection{Agar gel (sample \#1 and \#2)}

The composition of the TMM gel ${ }^{45}$ was modified in order to be compatible with our experimental setting. The main components of the gel are water, glycerol and agar, the first two compounds mainly contribute to the sound velocity value, while the last one contributes to the stiffness of the gel. The $\mathrm{Al}_{2} \mathrm{O}_{3}$ powder, which delivers the attenuation properties of the gel, had to be substituted with $\mathrm{SiO}_{2}$ because of its interaction with the magnetic field resulting in low MRI signal especially with $\mathrm{T}_{2}$ * sequences as for PRFS thermometry. The incorporation of $\mathrm{SiC}$, which mimics the backscattering properties along with $\mathrm{Al}_{2} \mathrm{O}_{3}$, was also suppressed as it was not mandatory for our purpose.

General procedure: Proportions of the different ingredients other than water used to reach a constant $290 \mathrm{ml}$ of final gel are provided in mass unit (gram): glycerol $=33.6, B A L=0.27$, agar $=9, \mathrm{SiO}_{2}(1.5 \mu \mathrm{m})=2.85, \mathrm{SiO}_{2}(1.5 \mu \mathrm{m})=2.64$. Silicon oxide was suspended in $50 \mathrm{ml}$ of degassed water and insonified with a $13 \mathrm{~mm}$ sonotrode for $2 \mathrm{~min}$ in. The BAL solution, glycerol, the silicon oxide mixture and degassed water (see Table 2) were added to a $400 \mathrm{ml}$ tared beaker. And under mechanical stirring the mixture was heated and then agar was added. The solution was heated at above $90^{\circ} \mathrm{C}$ for one hour. Then the gel was set to cool down under magnetic stirring and any water lost was compensated with degassed water. Then when the mixture reached about $40^{\circ} \mathrm{C}$; the emulsion (see Table 2), loaded with three drops of methylene blue, was added, homogenised and cool down. The volume fraction of PFOB in TMM was used to describe the MSD concentration (see Table 2).

\subsubsection{Gelatine gel (sample \#3 and \#4)}

The purpose of this section was to identify the dominant mechanism producing enhanced acoustic absorption among two hypotheses: 1) the MSD are directly converting the mechanical energy into thermal energy; 2 ) the MSD act as inelastic scatters producing mode conversion and re-emitting higher frequency than the incident one, with the higher frequencies being absorbed more effectively by the surrounding bulk gel. ${ }^{52}$ If the second hypothesis is true, the efficiency of micro-particles should be significantly decreased in a 
non-absorbent gel. If the first hypothesis is true, their efficiency should be comparable when embedded in an absorbent or non-absorbent bulk gel.

A non-acoustic absorbent gel was prepared with water, gelatine and benzalkonium chloride and its acoustic properties were measured. $9 \mathrm{~g}$ of gelatine (brand Vahiné), $285 \mathrm{mg}$ of BAL were added to $276 \mathrm{ml}$ of degassed water. Then the mixture was heated at $45^{\circ} \mathrm{C}$ for 5 10 min to ensure complete dissolution of the gelatine. The mixture was left to cool down to $25^{\circ} \mathrm{C}$ and poured in an open glass cylinder, with its base closed by paraffin film. Then $15 \mathrm{ml}$ of emulsion was added and then cooled drawn at $4^{\circ} \mathrm{C}$. For the control gel, we used the same protocol, but $285 \mathrm{ml}$ of degassed water was added.

\subsection{Physical characterization}

\subsubsection{Particle size}

The particle size distribution was assessed using a Mastersizer 2000 laser diffraction particle size analyser (Malvern Instruments, Orsay, France) equipped with Hydro2000S as sample dispersion unit (A) mod using the Mie light scatteringtheory. The refractive indices used were 1.305 for the PFOB and 1.333 for the dispersant (water). Several drops of the emulsion were added with a stirring of $500 \mathrm{rpm}$ to the sample dispersion unit. The Mie theory was used to determine the volume weighted mean diameter $\mathrm{D}[4,3]$ and the polydispersity was calculated as $\mathrm{d} 90 / \mathrm{d} 10 . \mathrm{d} 90$ is the diameter at which $90 \%$ of the sample's volume is comprised of droplets with a diameter less than this value. d10 is the diameter at which $10 \%$ of the sample's volume is comprised of droplets with a diameter less than this value. The size distribution histogram is shown in Figure $1 \mathrm{~b}$.

\subsubsection{Optical microscopy}

The optical microscopy was performed on an Olympus BX60 microscope (Olympus, Rungis, France) with $100 x$ magnification (see Figure 1c) and no spectral filter.

\subsubsection{Determination of volume fraction}

All spectra were recorded on a $400 \mathrm{MHz}$ Bruker Avance II spectrometer with a resonance frequency of $376.53 \mathrm{MHz}$ for ${ }^{19} \mathrm{~F}$. ${ }^{19} \mathrm{~F}-\mathrm{NMR}$ spectra were acquired using the inverse-gated 
decoupling technique. Each spectrum was the result of 256 scans with 131072 data points using a relaxation delay of $4 \mathrm{~s}$. Peak area was integrated using manufacturer standard software (Topspin, version 3.5pl7, Bruker, Wissembourg, France). A calibration curve was obtained using a mixture of $40 \mu \mathrm{l}$ of PFOB dissolved in $2.9004 \mathrm{~g}(4.068 \mathrm{ml})$ of $^{2} \mathrm{Et}_{2} \mathrm{O}$ and a dilution path produced various concentrations. Twenty $\mu$ l of water were diluted with $600 \mu l$ of $\mathrm{MeOH}$, then $600 \mu \mathrm{l}$ of various concentration $\mathrm{Et}_{2} \mathrm{O} / \mathrm{PFOB}$ mixture were added. For the titration, the volume of water was replaced by $20 \mu \mathrm{l}$ of emulsion and $600 \mu \mathrm{Et}_{2} \mathrm{O}$ were added instead of the mixture $\mathrm{Et}_{2} \mathrm{O} / \mathrm{PFOB}$. $\mathrm{Et}_{2} \mathrm{O}$ was used to solubilise the PFOB and $\mathrm{MeOH}$ to have a homogeneous solution. The mixture was homogenised, then $500 \mu \mathrm{l}$ of this solution were added to the NMR tube, followed by a coaxial capillary filled with a solution of sodium trifluoroacetate (TFA) salt in $\mathrm{D}_{2} \mathrm{O}(50 \mathrm{mg} / \mathrm{ml})$. The latter was used as external reference and was kept the same for all experiments. The TFA salt was chosen because of the proximity of the signal ascribed to its $\mathrm{CF}_{3}$ group compared to the $\mathrm{CF}_{3}$ of the $\mathrm{PFOB}$, at -75.96 and 80.15 ppm respectively, thus avoiding problem of keeping a uniform field over a long range. The ratio of integration of the external standard over that of PFOB was plotted against the volume fraction of PFOB to create a calibration curve. All measurements were performed on triplicate samples.

\subsubsection{Acoustic velocity measurement}

Measurement of sound velocity was performed using the setup schematically described in SI. During a measurement, a burst made of one sinusoidal period was generated by a wave function generator (model 33250A from Agilent, les ulis, France). The burst intensity was amplified 500 times using a RF power amplifier (model A 10-100 from M2S, Argelès sur Mer, France), then went through a duplixer (model RDX-6 from RITEC, Warwick, USA) and eventually reached a transducer. We used three transducers (from Panasonics, Gennevilliers, France) that differ by their resonance frequency; 2.25, 5 and $10 \mathrm{MHz}$. The burst sinusoidal frequency was chosen to match the transducer central frequency. The transducer was in contact with a gel immersed in water. The short pressure wave produced by the transducer propagated though the gel until it reached the opposed edge of the gel that is in contact with a metallic surface. The wave was reflected back to the transducer and converted into an electrical signal that was sent by the duplixer to a pre-amplifier (PAS-0.1-20 from RITEC), then to a Broadband receiver (BR-640A from RITEC). The signal was visualised on an 
oscilloscope (model WaveSurfer 424 from Lecroy, Courtaboeuf, France) and recorded after averaging over 400 sweeps. The same measurement was performed after removing the gel where the signal propagates over exactly the same distance in water. The squared signal amplitude was analysed. The temporal position of reflected pulses (determined from its center of gravity) was simply a multiple $n$ times the time $2 \tau$ to travel forward and back through the gel. The corresponding forward and back travelling distance, that is twice the gel thickness $\delta$, was determined from the signal measured after removing the gel and using the known ultrasound velocity of water (that is $1480 \mathrm{~m} / \mathrm{s}$ at a temperature of $20^{\circ} \mathrm{C}$ ). The sound velocity in the gel was then calculated as an average value of sound velocities derived from $\tau$ and $\delta$ for the $n$ reflected pulses.

\subsection{Thermo-acoustic investigation of TMM gels doped with MSD}

\subsubsection{Focused ultrasound}

A spherical MR-compatible phased array HIFU transducer (Imasonic, Besançon, France) composed of 256 elements was used for generation of focused ultrasound. The main parameters are frequency range $974-1049 \mathrm{kHz}$, focal length $130 \mathrm{~mm}$ and aperture $140 \mathrm{~mm}$. The transducer was supplied by a 256-channel beam former (Image Guided Therapy, Pessac, France). The HIFU transducer was placed horizontally on the MR table and emitted vertically. Each gel sample (agarose-based and gelatine-based) was placed in an ultrasound coupling holder filled with degassed water and maintained with a standardised setup using resin moulds (Figure $2 a, b$ ). A standard ultrasonic gel was added on the sample top to avoid interface reflection of the waves. The standardised setup assured reproducible positioning of the sample and a $35 \mathrm{~mm}$ identical depth of the focus through the series of experiments. HIFU sonication was performed using the electronic steering of the beam thus describing iteratively a discrete circular pattern of $4 \mathrm{~mm}$ diameter composed of 16 points regularly distributed on the circumference. This sonication pattern was chosen in order to average eventual local inhomogeneities of the TMM gel or MSD distribution in the gel, which could exist at infra-millimeter scale. The pattern was covered in $1.65 \mathrm{~s}$ and the trajectory was repeated 20 times, yielding a total treatment time of $33 \mathrm{~s}$. The applied acoustic power was $94 \mathrm{~W}$ and the beam emission duty cycle was set at 70\% (sample \#1 absorbent gel and \#3 nonabsorbent ge) or $90 \%$ (sample \#2 absorbent and \#4 non-absorbent). This is respectively 
equivalent to $1.4 \mathrm{~s}$ or $1.8 \mathrm{~s}$ cumulated sonication time per ietration locus, corresponding to an effective duty cycle of sonication of droplets (as seen at a given location in the gel) of 4.2\% and 5.5\%. Sonication planning and hardware control was achieved using Thermoguide ${ }^{\mathrm{TM}}$ software (Image Guided Therapy, Bordeaux, France).

The mechanical effect of HIFU sonication on the MSD size distribution was investigated in a liquid emulsion using a fixed focal point beam, applied power $135 \mathrm{~W}$, pulse duration $90 \mathrm{~ms}$, duty cycle $90 \%$, total duration of the sonication paradigm $33 \mathrm{~s}$. To this purpose $3 \mathrm{ml}$ of emulsions of MSD stabilized with $\mathrm{F}_{6} T A C_{7}$ or $\mathrm{F}_{8} T A C_{7}$ respectively were inserted in an ultrasound-transparent container centered on the focal point and exposed one, two or three times to the sonication paradigm, separated by 5 minutes intervals. The particle size distribution was measured using the Mastersizer 2000 laser diffraction particle size analyser as described above.

\subsubsection{MR thermometry}

All measurements were performed using a $3 T$ whole body MR system (Prisma Fit, Siemens, Erlangen, Germany). An 11-cm diameter receive only loop coil was used and placed around the sample. High resolution MR thermometry was performed by Proton Resonance Frequency Shift (PRFS) thermometry, ${ }^{53}$ which provides a precise monitoring of temperature evolution at a high frame rate and with a millimetre resolution. To this purpose we used a segmented GRE-EPI sequence with main parameters; TE (echo time) =10ms, TR (repetition time $)=25 \mathrm{~ms}$, flip angle $=8^{\circ}, \mathrm{BW}$ (bandwidth) $=550 \mathrm{~Hz} /$ pixel, acquisition matrix $128 \times 128$, slice thickness $=5 \mathrm{~mm}$, FOV $=128 \times 128 \mathrm{~mm}$, voxel size $=1 \times 1 \times 5 \mathrm{~mm}^{3}$, temporal resolution $=1$ s., number of averages NSA (number of averages) $=1$, phase encoding direction = head-foot (HF), spectroscopic fat saturation.

The MSD effect of enhancing the HIFU absorption was measured with two normalized metrics: 1) a differential heating factor was defined as the additional elevation of temperature at the focal point considered at the end point of the sonication interval divided by the total emitted acoustic energy of the sonication [unit ${ }^{\circ} \mathrm{C} / \mathrm{kJ}$ ], and 2 ) an integral enhancement of heating was defined as the thermal energy deposited in the MR slice integrated over the voxels heated at least $+1^{\circ} \mathrm{C}$ above baseline at the end point of the sonication interval and divided by the total emitted acoustic energy of the sonication 
[dimensionless]. The thermal energy was calculated as the product temperature elevation times estimated heat capacity.

A total of 38 sonications were analyzed in absorbent or non-absorbent gels doped with MSD and compared with 36 baseline sonications in MSD-free gels.

\subsubsection{Treatment planning}

Positioning of the focal point was prescribed using 3D high resolution images acquired with an isotropic gradient echo sequence with the following parameters: TE $=2.46 \mathrm{~ms}, \mathrm{TR}=5.36$ ms, flip angle $=10^{\circ}, B W=390 \mathrm{~Hz} /$ pixel, slices per slab $=192, \mathrm{FOV}=256 \times 256 \mathrm{~mm}$, slice thickness $=0.8 \mathrm{~mm}$, voxel size $=1.00 \times 1.00 \times 1.28 \mathrm{~mm}$. The focal plane was set at $35 \mathrm{~mm}$ depth in the sample in the direction of propagation of the HIFU beam.

\subsection{4. ${ }^{19} F M R I$ of MSD loaded TMM samples}

${ }^{19} \mathrm{~F}$ image acquisition of the samples was performed using an RF-spoiled 2D gradient-recalled echo (GRE) pulse sequence in order to confirm the uniform distribution of micro-particles in the gel. A dedicated ${ }^{19} \mathrm{~F}$ quadrature RF-birdcage coil was used, switchable between ${ }^{1} \mathrm{H}$ and ${ }^{19} \mathrm{~F}$ (Clinical MR solutions, Brookfield, WI). ${ }^{54}$ The resonance frequency for ${ }^{19} \mathrm{~F}$ was 115.95 $\mathrm{MHz}$. The coil had internal diameter $4.4 \mathrm{~cm}$ and $6 \mathrm{~cm}$ length. Due to the small size of the coil, subsamples were cut from the TMM gel native and doped with $0.1 \%$ and $0.5 \% \mathrm{MSD} v / \mathrm{v}$ and stacked parallel inside the coil in a miniature water bath, which improved the local magnetic field homogeneity (passive shimming). Main parameters of the gradient echo ${ }^{19} \mathrm{~F}$ sequence were $\mathrm{TR}=300 \mathrm{~ms}, \mathrm{TE}=5.07 \mathrm{~ms}, \mathrm{NSA}=25, \mathrm{BW}=325 \mathrm{~Hz} /$ pixel, matrix $96 \times 96, \mathrm{FOV}$ $=128 \times 128 \mathrm{~mm}$, flip angle $=70^{\circ}$, slices per slab $=8$, slice thickness $=10 \mathrm{~mm}$, pulse duration $=$ $2 \mathrm{~ms}$, in plane voxel size $=1.67 \times 1.33 \mathrm{~mm}^{2}$.

\subsubsection{Ultrasonography}

The acquisition of ultrasound images to investigate the attenuation of the backscattered signal from gel samples was performed using a clinical US system (ACUSON Antares, Siemens Healthcare, Mountain View, CA). The abdominal imaging probe composed of 192 elements operated in harmonic mode at 2.2 MHz. Appropriate near field coupling and far field full absorption of the acoustic field was implemented to avoid beam reflections. 


\section{Results and discussion}

409

410

411

412

413

414

415

416

417

418

419

420

421

422

423

424

425

426

427

428

429

430

431

432

433

434

435

\subsection{Characterization of microdroplets}

As shown in Table 3, for all surfactants, except for the $\mathrm{F}_{8} \mathrm{TAC}_{13}$ and $\mathrm{F}_{8} \mathrm{TAC}_{17}, \mathrm{MSD}$ possess a size distribution in the micrometric range. For a given hydrophobic tail, the larger the polar head, the smaller the resulting MSD size until reaching a plateau. For both series, the optimal polar head size was found to be around 12 Tris units. Above this value of DPn, the MSD size remains constant for both hydrophobic tails. Furthermore, the size decreased by a factor 6.5 between DPn 7 and 13 for the $F_{8}$ series, while for the $F_{6}$ series the size decreases only by a factor 2.5 between DPn 7 and 12 . On one hand, this trend can be explained by the fact that, during the emulsification process, increasing the polar head size increases the steric hindrance and hence the stability of the MSD until an optimal size is reached. ${ }^{41}$ On the other hand, once this plateau is achieved (for DPn $\geq 12$ ), the hydrophobic tail seems to play a significant role, as the MSD diameter obtained for $\mathrm{F}_{8} \mathrm{TAC}_{13}$ is twice smaller than for $\mathrm{F}_{6} \mathrm{TAC}_{12}$. This might be either due to an optimal volume ratio between the polar head and the hydrophobic tail of the surfactant and/or to a higher concentration of available surfactant (in the form of free monomer or micelles) in the dispersant phase (i.e. water). In the case of $\mathrm{F}_{8} \mathrm{TAC}_{13}$ this leads to a finer emulsion. The surfactant concentration is about 8 (for $\mathrm{F}_{6} \mathrm{TAC}_{12}$ ) and 280 (for $\mathrm{F}_{8} \mathrm{TAC}_{13}$ ) times over the critical micellar concentration (CMC). It is noteworthy that this difference in droplet size cannot be ascribed to a difference in surface tension between PFOB and water in the presence of each surfactant as they are similar with $12.1 \mathrm{mN}$ $\mathrm{m}^{-1}$ for $\mathrm{F}_{6} \mathrm{TAC}_{12}$ and $10.4 \mathrm{mN} \mathrm{m}{ }^{-1}$ for $\mathrm{F}_{8} \mathrm{TAC}_{13}{ }^{42}$ Emulsions were stable for several weeks in the refrigerator which is in good agreement with previous work from other groups. ${ }^{15}$ Our group has previously shown that the surfactant type $F_{6} T A C_{7}$ is perfectly biocompatible after i.v. injection in mice (LD50 above $4.5 \mathrm{~g} / \mathrm{kg}){ }^{43}$

Given that droplets need to be smaller than $6 \mu \mathrm{m}$ in diameter to avoid capillary thrombosis, and that the larger the droplets diameter the lower the energy required for their vaporisation, ${ }^{55} \mathrm{MSD}$ made with either $\mathrm{F}_{8} \mathrm{TAC}_{7}$ or $\mathrm{F}_{6} \mathrm{TAC}_{7}$ surfactant appear to be the best candidates. For the first emulsion the $d 90$ is above $7 \mu \mathrm{m}$, while for the second emulsion, d90 was below $6 \mu \mathrm{m}$ in diameter which makes the latter one a better candidate. However, as shown by the MSD size distribution in Figure 1.b, the droplets obtained with $\mathrm{F}_{6} \mathrm{TAC}_{7}$ 
displayed a very high polydispersity $(\mathrm{d} 90 / \mathrm{d} 10=4.00)^{42}$ which was also confirmed by optical microscopy (Figure 1.c).

The method of MSD titration was modified from the one published by Astafyeva et $\mathrm{al}^{42}$ in order to obtain a totally homogenous solution containing both PFOB and water. To do so, we used a ternary system made of a mixture of methanol and diethyl ether, the latter being used to ensure complete solubilisation of PFOB in the solution. ${ }^{56}$ The concentration of PFOB in the emulsion was thus estimated to be $11.6 \pm 0.9 \%$, which indicated a loss of about $15 \%$ of water during the synthesis process.

\subsection{MR compatibility and acoustics properties}

The final gel composition demonstrated perfect MR compatibility in term of local magnetic susceptibility and was shown to be homogeneous at the observation scale of the MR (mmrange), as illustrated in Figure 2 a,b. High resolution GRE proton 3D images also demonstrated that no macroscopic air bubbles were present.

The sound velocity of our TMM was found $1522 \pm 5 \mathrm{~m} / \mathrm{s}$ at $1 \mathrm{MHz}, 1521 \pm 5 \mathrm{~m} / \mathrm{s}$ at $2.5 \mathrm{MHz}, 1528 \pm 5 \mathrm{~m} / \mathrm{s}$ at $5 \mathrm{MHz}$ and $1532 \pm 5 \mathrm{~m} / \mathrm{s}$ at $10 \mathrm{MHz}$. These values are close to the speed of sound in soft tissue in vivo (approx. $1540 \mathrm{~m} / \mathrm{s}$ ). Furthermore, usually US devices are calibrated at this speed of sound. ${ }^{57}$ The speed of sound of our TMM is a little bit lower than the one found in the original gel from Ramnarine et al. ${ }^{45}$ Even if some TMM components were changed, the sound velocity is only proportional to the quantity of water, agar and glycerol and these were used in the same proportion as Ramnarine et al. ${ }^{58}$ Furthermore, approximately the same sound velocity is measured for the same TMM but without silica (Data not shown). This discrepancy could be due to the use of different brand of agarose, given that their mechanical properties change according to their molecular weight, ${ }^{59}$ and that change in molecular weight affects the gel elasticity with an elasticity decreasing proportionally with the molecular weight.

$$
v=\sqrt{\frac{C i j}{\rho}}
$$

$C_{i j}$ represents the stiffness coefficient, $\rho$ the mass density and $v$ the speed of sound. ${ }^{60}$

\subsection{Effect of MSD concentration on acoustic properties of the gel (echogenicity)}


Four concentrations of MSD using $\mathrm{F}_{6} \mathrm{TAC}_{7}$ surfactant were embedded into the TMM to study their impact on the acoustic and echogenic properties. The sound velocity in the different TMM loaded with MSD decreased linearly as a function of their concentration, as PFOB sound velocity is much lower, $623 \mathrm{~m} / \mathrm{s}$, than the control TMM, $1522 \mathrm{~m} / \mathrm{s.}^{40,42}$

The MSD were not hyper-echogenic in harmonic ultrasound images at $2.5 \mathrm{MHz}$ (see Figure 3) but increasing the MSD concentration induced a significant enhancement of the attenuation of the backscattered acoustic signal as the far field signal become darker as the concentration rises. The backscattered signal was plotted against the depth of the signal source in the image, independently for the four different concentration TMM and fits to an exponential decay function $f(x)=\exp \left(-a^{*} x\right)$ with the linear attenuation coefficient " $a$ " decreasing linearly with droplets concentration.

\subsection{MSD interaction with HIFU beam}

\subsubsection{In absorbent TMM}

The ${ }^{19} \mathrm{~F}-\mathrm{MR}$ imaging confirmed that the droplets were evenly distributed throughout the gel on the scale of the current resolution (Figure 4).

Only the two lowest MSD concentrations were tested for HIFU thermal enhancement, 0.1 and $0.5 \% \mathrm{v} / \mathrm{v}$. These concentrations are more realistic when considering the feasible delivery in living tissue. The additional temperature elevation was approximately $9^{\circ} \mathrm{C}$ and $15^{\circ} \mathrm{C}$ for $0.1 \%$ and $0.5 \%$ concentration of MSD respectively, as illustrated in Figure 2 $d-f$ and Figure $5 a$, which corresponds to an impressive thermal dose amplification by a factor on the order of $2^{9}$ and $2^{15}$ respectively, according to Sapareto. ${ }^{61}$

Table 4 shows the results for the two defined metrics of HIFU enhancing effect in two series of TMM samples, the precision of measurements, the values of the two tailed $p$-test and the confidence interval $(\mathrm{Cl})$. As the $\mathrm{p}$-value was always inferior to $10^{-5}$ in each comparative branch, the reported number of replicates is clearly sufficient and allowed an estimation of the enhanced heating efficacy with $6 \%$ precision (second metric). This value is considered sufficient for in vivo application, given the other potential sources of errors in a biological system that largely overweight this uncertainty.

The additional temperature elevation per unit of emitted acoustic energy (first metric) was found $4.30 \pm 0.39{ }^{\circ} \mathrm{C} / \mathrm{kJ}$ in gel series \#1 with $0.1 \%$ concentration of MSD, $3.45 \pm$ $0.22^{\circ} \mathrm{C} / \mathrm{kJ}$ in gel series \#2 with $0.1 \%$ concentration of MSD, $7.32 \pm 0.57^{\circ} \mathrm{C} / \mathrm{kJ}$ in gel series \#1 
with $0.5 \%$ concentration of $\mathrm{MSD}$ and $5.15 \pm 0.28{ }^{\circ} \mathrm{C} / \mathrm{kJ}$ in gel series \#2 with $0.5 \%$ concentration of MSD.

The application of the second metric of HIFU enhancing effect yielded an integral enhancement of the thermal energy produced in the MR slice of $(3.56 \pm 0.44) \times 10^{-3}$ in the gel series \#1 with $0.1 \%$ concentration of MSD, $(4.03 \pm 0.32) \times 10^{-3}$ in the gel series \#2 with $0.1 \%$ concentration of MSD $(6.51 \pm 0.72) \times 10^{-3}$ in the gel series \#1 with $0.5 \%$ concentration of MSD, and $(7.08 \pm 0.40) \times 10^{-3}$ in the gel series \#2 with $0.5 \%$ concentration of MSD. The precision and the confidence interval demonstrated relevant and reproducible measurements.

The relationship between the MSD concentration and HIFU-induced heat generation was not linear as demonstrated by the two metrics. This relationship was also observed with PSNE where increasing the droplet concentration from $0.008 \%$ to $0.020 \%$ result in similar lesion volume in a polyacrylamide gel. ${ }^{62}$

Repeated acquisition of MR temperature maps in the plane parallel to the HIFU beam propagation showed no evidence of pre- or post-focal thermal build up during the volumetric HIFU exposure in presence of MSD (Figure 1.c). The heating patterns were localised around the prescribed position of the focal plane and matched the near-elliptical shape predicted by theory (e.g. non-distorted). These findings are very important in the context of the lesion predictability. According to Chen et $\mathrm{al}^{63}$ the shape of the lesion was demonstrated to change from a cigar shape to a teardrop shape in the presence of an ultrasound contrast agent around $1 \mathrm{MHz}$ frequency. Lo and Kripfgans ${ }^{64}$ found similar results by increasing the amplitude or the number of pulses. In our study, we have demonstrated that the interaction between the HIFU beam and the home-made MSD did not result in the distortion of the lesion shape, within the range of applied power and duty cycle of sonication. This discrepancy might be explained by a different mechanism of interaction of MSD with the acoustic waves. PFC possess a high ability to dissolve gas, especially oxygen, and were reported in literature as oxygen carriers. ${ }^{39}$ As postulated by Rapoport et al, ${ }^{34}$ during the peak rarefactional pressure, the dissolved gas forms a bubble inside the MSD shell, whereas the PFOB stay in liquid form. These bubbles are capable of undergoing stable cavitation but are less prone to IC which might explain the difference of behaviour compared to other study. ${ }^{26}$ 

droplets

HIFU sonication yielded a low temperature elevation of only $1.2^{\circ} \mathrm{C}$ in average in the nonabsorbent gel samples. Comparing the results of heating enhancement by $0.5 \%$ MSD in absorbent and non-absorbent gel according to Tables 4 and 5 for the second metric and the surfactant $F_{6} T A C_{7}$ show that the enhancement of the HIFU thermal effect was mainly due to the presence of MSD ( $90 \%$ of the effect) and the intrinsic acoustical absorption properties of the TMM had only a slight impact. The first metric was not used for this comparison as it may be biased by the different heat diffusion coefficient of the gel matrix.

\subsubsection{Effect of choice of surfactant on the MSD ultrasound absorption}

The best potential candidate surfactant according to Table 3 regarding the average diameter $\left(F_{8} T A C_{7}\right.$ and $\left.F_{6} T A C_{7}\right)$ were investigated for comparative MSD effect on the HIFU absorption in non-absorbent gel (Table 5, metric 2). The other surfactants were excluded because of the small size of corresponding MSD. The integral enhancement of the thermal energy deposition in the slice, comparing the $0 \%$ and $0.5 \%$ concentration of MSD was $6.1 \times 10^{-3}$ in non-absorbent gel using $\mathrm{F}_{6} \mathrm{TAC}_{7}$ and $4.4 \times 10^{-3}$ in non-absorbent gel using $\mathrm{F}_{8} \mathrm{TAC}_{7}$ surfactant. These MSD have comparable ultrasound absorption, but the choice of the surfactant is important for an optimal effect of enhanced HIFU thermal therapy.

\subsubsection{Effect of repeated HIFU sonications on MSD}

Table 6 showed that after the repetition of HIFU exposure in the non-absorbent gel at the same location, a slight decrease of $5 \%$ of thermal deposition per cycle was observed between the first shot and the second shot and $10 \%$ between the first shot and the third shot, this tendency is also illustrated with graphical plots in Figure 5.b. This behaviour confirms that the interaction between the HIFU beam and MSD is mainly a reversible process within the range of sonication parameters used in our study. The measurable loss of heat deposition efficacy between each sonication was observed under static conditions (i.e. no blood flow) and indicated that the MSD distribution and concentration are marginally 
evolving, for instance some droplets can coalesce or some of the PFC can be dissolved. ${ }^{65}$ One advantage of the MSD stability against repeated HIFU sonication is the reduction of the risk of embolism. ${ }^{26}$ Another advantage is the possibility to use respiratory gated sonication, i.e. delivering temporal fractions of energy periodically and synchronized to tissue motion ${ }^{66}$ in order to target the same tissue despite patient breathing.

The repeated exposure of MSD liquid emulsion to HIFU beams yielded a reduction of the average diameter in the range $25 \%$ to $75 \%$, depending on the nature of surfactant and on the number of applied cycles of sonication, as shown in Table 7. This result supports the safe use of described endovascular MSD in vivo, as their size decreased upon application of HIFU, without a risk of capillary embolism. Due to the large pool of circulating MSD in the blood, the local denaturation (eg size reduction) of some MSD is not expected to impact the final efficacy as new MSD are continuously supplied to the treated area.

\subsubsection{Perspectives}

In this proof of concept study, we demonstrated significant enhancement of the HIFU absorption in presence of tailored-made sono-sensitive MSD, however, a parametric study was not performed to determine the influence of the acoustic intensity levels and duration of sonication on the enhancement effect. These investigations are required in order to optimize the HIFU pulse sequence to be applied to the respective MSD.

Future in vivo studies need to be performed to confirm the thermal enhancement produced by the current MSD. As compared to the present in vitro study, there are some different conditions to be considered. Firstly, the fraction of acoustic power transferred to tissue will change as the absorption properties, stiffness and viscosity will be different from our TMM. Secondly, the droplets will be confined to the blood vessels as we target tumours in highly perfused organs (e.g. kidney or liver). Thirdly, we may be not able to reach, in vivo, the droplet concentration added to the gels, however, significant dose reduction is likely to be achieved. According to Figure $5 \mathrm{a}$, the $0.1 \%$ MSD gel was heated approximately 2.5 times more than the baseline gel. This ratio largely exceeds the therapeutic need. One should also note in this study that we used not more than 135 acoustic watt. Literature reports ${ }^{67,68}$ mention significantly larger acoustic powers in vivo (ie between $300 \mathrm{~W}$ and $800 \mathrm{~W}$ ). 
Unlike phase shift nanoemulsions, ${ }^{30}$ when using our micro-droplets, the sonication can start a few minutes after the iv injection, as there is no need to wait some accumulation period. Overall, a HIFU treatment session comprises 10 to 30 minutes of active sonication interval and the MSD are required to be stable during a relatively short period of time.

The reported experiments were performed at ambient temperature to avoid a timeconsuming procedure of stabilizing the TMM temperature at $37^{\circ} \mathrm{C}$ inside the MR bore. The temperature can also influence the energy required for ADV and/or IC, knowing that ADV depends both on thermal and acoustic parameters and the latter will foster the physical interaction of HIFU beam with MSD. ${ }^{65}$ The pool of MSD interacting with the HIFU beam will be continuously refreshed in vivo due to the blood flow, supporting a higher efficiency. Overall, the final efficacy in vivo remains to be determined.

\section{Conclusion}

As a proof of concept, MSD with a PFOB core were synthesised and introduced into a MRI compatible TMM, in order to enhance the thermal deposition of focused ultrasound. We expect that this effect will allow a decrease in the energy and the time required to perform tumour ablation, and to reduce the risks of HIFU treatment side effects by decreasing the thermal build up in the near and far field.

By varying the chemical structure of an in-house fluorinated surfactant, the size of the MSD could be tuned in the range 0.67 to $4.07 \mu \mathrm{m}$. These droplets were embedded in a common agar-based TMM, which mimics the acoustic properties of soft tissue. The gel composition was modified to be $\mathrm{MR}$ compatible by substituting the $\mathrm{Al}_{2} \mathrm{O}_{3}$ by $\mathrm{SiO}_{2}$ and the acoustic properties of this TMM new formulation were assessed, yielding a sound velocity very similar to soft tissue.

TMM loaded with various concentrations of MSD did effectively enhanced the heating efficiency around the focal point, potentially reducing treatment time for a given target level of temperature. We noticed that the thermal deposition was not linear with MSD concentration in TMM gels, and that the best specific activity was obtained in vitro at $0.1 \%$ concentration. Furthermore, the reiteration of the HIFU burst at the same location only lessened by about $5 \%$ the efficacy of heat deposition between each repetition in static conditions (non-circulating droplets). Moreover, the acoustic properties of the material had 
627 little if any influence on the efficiency of the MSD, translated into similar enhancement in 628 both absorbent and non-absorbent gel. Further investigations are required to assess the 629 exact mechanism of acoustic energy conversion into thermal energy, specifically if the 630 droplets undergo phase transition or not. Future studies are planned using ex vivo perfused 631 kidney in order to prove that this effect is transposable to highly perfused organs.

632 


\section{References}

635

636

637

638

639

640

641

642

643

644

645

646

647

648

649

650

651

652

653

654

655

656

657

658

659

660

661

662

663

664

665

666

667

668

669

670

671

672

673

674

675

676

677

678

679

680

681

1 J. Kennedy, Nat. Rev. Cancer, 2005, 5, 321-327.

2 C. Moonen, B. Quesson, R. Salomir, F. Vimeux, J. de Zwart, J. van Vaals, N. Grenier and J. Palussière, Neuroimaging Clin. N.. Am, 2001, 11, 737-47, xi.

3 D. Tyshlek, J.-F. Aubry, G. ter Haar, A. Hananel, J. Foley, M. Eames, N. Kassell and H. H. Simonin, J. Ther. Ultrasound, 2014, $2,2$.

4 O. Al-Bataineh, J. Jenne and P. Huber, Cancer Treat. Rev., 2012, 38, 346-353.

5 J.-F. Aubry, K. B. Pauly, C. Moonen, G. ter Haar, M. Ries, R. Salomir, S. Sokka, K. M. Sekins, Y. Shapira, F. Ye, H. Huff-Simonin, M. Eames, A. Hananel, N. Kassell, A. Napoli, J. H. Hwang, F. Wu, L. Zhang, A. Melzer, Y. Kim and W. M. Gedroyc, J. Ther. Ultrasound, 2013, 1, 13.

6 J. Kennedy, F. Wu, G. ter Haar, F. Gleeson, R. Phillips, M. Middleton and D. Cranston, Ultrasonics, 2004, 42, 931-935.

7 L. G. Merckel, L. W. Bartels, M. O. Köhler, H. J. G. D. van den Bongard, R. Deckers, W. P. T. M. Mali, C. A. Binkert, C. T. Moonen, K. G. A. Gilhuijs and M. A. A. J. van den Bosch, Cardiovasc. Intervent. Radiol., 2013, 36, 292-301.

8 J. Vidal-Jove, E. Perich and M. Alvarez del Castillo, Ultrason. Sonochem., 2015, 27, 703706.

9 F. Wu, Z. Wang, Y. Cao, W. Chen, J. Bai, J. Zou and H. Zhu, Br. J. Cancer., 2003, 89, 2227-2233.

10Y.-F. Zhou, World J. Clin. Oncol., 2011, 2, 8-27.

11 Y.-S. Tung, H.-L. Liu, C.-C. Wu, K.-C. Ju, W.-S. Chen and W.-L. Lin, Ultrasound Med. Biol, 2006, 32, 1103-1110.

12 S. E. Jung, S. H. Cho, J. H. Jang and J.-Y. Han, Abdom. Imaging, 2011, 36, 185-195.

13 J.-J. Li, G.-L. Xu, M.-F. Gu, G.-Y. Luo, Z. Rong, P.-H. Wu and J.-C. Xia, World J.

Gastroentero.l, 2007, 13, 2747-2751.

14 Y. Y. Seo, J. H. O, H. S. Sohn, E. K. Choi, I. D. Yoo, J. K. Oh, E. J. Han, S. E. Jung and S. H. Kim, Nucl. Med. Mol. Imaging, 2011, 45, 268-275.

15 M. Zhang, M. L. Fabiilli, K. J. Haworth, F. Padilla, S. D. Swanson, O. D. Kripfgans, P. L.

Carson and J. B. Fowlkes, Acad. Radiol., 2011, 18, 1123-1132.

16C. C. Coussios, C. H. Farny, G. Ter Haar and R. A. Roy, Int. J. Hyperthermia, 2007, 23, $105-120$.

17 S. Umemura, K. Kawabata and K. Sasaki, IEEE Trans. Ultrason. Ferroelectr. Freq.

Control, 2005, 52, 1690-1698.

18T. Yu, G. Wang, K. Hu, P. Ma, J. Bai and Z. Wang, Urological Research, 2004, 32, 14-19.

19L. C. Moyer, K. F. Timbie, P. S. Sheeran, R. J. Price, G. W. Miller and P. A. Dayton, J.

Ther. Ultrasound, 2015, 3, 7.

20 S. Sokka, R. King and K. Hynynen, Phys. Med. Biol., 2003, 48, 223-241.

21 O. D. Kripfgans, J. B. Fowlkes, D. L. Miller, O. P. Eldevik and P. L. Carson, Ultrasound Med. Biol., 2000, 26, 1177-1189.

22 Y. Zhou, J. Ther. Ultrasound., 2015, 3, 20.

23 O. D. Kripfgans, C. M. Orifici, P. L. Carson, K. A. Ives, O. P. Eldevik and J. B. Fowlkes, IEEE Trans. Ultrason. Ferroelectr. Freq. Control, 2005, 52, 1101-1110

24C.-Y. Lin and W. G. Pitt, Biomed Res. Int., 2013, 2013, 404361.

25T. Giesecke and K. Hynynen, Ultrasound Med. Biol., 2003, 29, 1359-1365.

26 N. Rapoport, K. H. Nam, R. Gupta, Z. Gao, P. Mohan and A. Payne, J. Control. Release, 2011, 153, 4-15. 
27 A. H. Lo, O. D. Kripfgans, P. L. Carson, E. D. Rothman and J. B. Fowlkes, IEEE Trans. Ultrason. Ferroelectr. Freq. Control, 2007, 54, 933-946.

28 M. Viallon, L. Petrusca, V. Auboiroux, T. Goget, L. Baboi, C. D. Becker and R. Salomir, Ultrasound Med. Biol., 2013, 39, 1580-1595.

29 K. C. Schad and K. Hynynen, Phys. Med. Biol., 2010, 55, 4933-4947.

30J. A. Kopechek, E. Park, C.-S. Mei, N. J. McDannold and T. M. Porter, J. Healthc. Eng., 2013, 4, 109-126.

31 P. S. Sheeran, V. P. Wong, S. Luois, R. J. McFarland, W. D. Ross, S. Feingold, T. O. Matsunaga and P. A. Dayton, Ultrasound Med. Biol, 2011, 37, 1518-1530.

32P. A. Mountford, W. S. Smith and M. A. Borden, Langmuir, 2015, 31, 10656-10663.

33 T. O. Matsunaga, P. S. Sheeran, S. Luois, J. E. Streeter, L. B. Mullin, B. Banerjee and P. A. Dayton, Theranostics, 2012, 2, 1185-1198.

34 N. Rapoport, Wiley Interdiscip. Rev. Nanomed. Nanobiotechnol., 2012, 4, 492-510.

35P. Zhang and T. Porter, Ultrasound Med. Biol., 2010, 36, 1856-1866.

36O. D. Kripfgans, M. Zhang, M. L. Fabiilli, P. L. Carson, F. Padilla, S. D. Swanson, C.

Mougenot, J. B. Fowlkes and C. Mougenot, J. Acoust. Soc. Am., 2014, 135, 537-544.

37 M. Zhang, M. L. Fabiilli, K. J. Haworth, J. B. Fowlkes, O. D. Kripfgans, W. W. Roberts,

K. A. Ives and P. L. Carson, Ultrasound Med. Biol., 2010, 36, 1691-1703.

38C. I. Castro and J. C. Briceno, Artif. Organs, 2010, 34, 622-634.

39J. G. Riess and M. P. Krafft, Biomaterials, 1998, 19, 1529-1539.

40 M. P. André, T. Nelson and R. Mattrey, Invest. Radiol.

41 T. F. Tadros, in Emulsion Formation and Stability, Wiley-VCH Verlag GmbH \& Co.

KGaA, 2013, pp. 1-75.

42 K. Astafyeva, L. Somaglino, S. Desgranges, R. Berti, C. Patinote, D. Langevin, F.

Lazeyras, R. Salomir, A. Polidori, C. Contino-Pepin, W. Urbach and N. Taulier, J. Mater.

Chem. B, 2015, 3, 2892-2907.

43 J. Maurizis, M. Azim, M. Rapp, B. Pucci, A. Pavia, J. Madelmont and A. Veyre,

Xenobiotica, 1994, 24, 535-541..

44L. Zarif, J. Riess, B. Pucci and A. Pavia, Biomater. Artif. Cells. Immobilization Biotechnol., 1993, 21, 597-608.

45 K. Ramnarine, T. Anderson and P. Hoskins, Ultrasound Med. Biol., 2001, 27, 245-250.

46C. Contino-Pepin, J. Maurizis and B. Pucci, Curr. Med. Chem. Anticancer Agents, 2002, 2, 645-665.

47 Y. Singh, J. G. Meher, K. Raval, F. A. Khan, M. Chaurasia, N. K. Jain and M. K.

Chourasia, J. Control. Release, 2017, 252, 28-49.

48 J. Browne, K. Ramnarine, A. Watson and P. Hoskins, Ultrasound Med. Biol., 2003, 29, 1053-1060.

49M. O. Culjat, D. Goldenberg, P. Tewari and R. S. Singh, Ultrasound Med. Biol., 2010, 36, 861-873.

50K Zell and J I Sperl and M W Vogel and R Niessner and C Haisch, Phys. Med. Biol, 2007, 52, N475.

51 A. Dabbagh, B. J. J. Abdullah, C. Ramasindarum and N. H. Abu Kasim, Ultrason.

Imaging, 2014, 36, 291-316.

52 S. A. Goss, L. A. Frizzell and F. Dunn, Ultrasound Med. Biol., 1979, 5, 181-186.

53 Y. Ishihara, A. Calderon, H. Watanabe, K. Okamoto, Y. Suzuki and K. Kuroda, Magn

Reson Med., , DOI:10.1002/mrm.1910340606.

54O. Lorton, J.-N. Hyacinthe, S. Desgranges, L. Gui, A. Klauser, Z. Celicanin, L. A. Crowe, F. Lazeyras, E. Allémann, N. Taulier, C. Contino-Pépin and R. Salomir, J. Magn. Reson., 2018, 295, 27-37. 
55O. Kripfgans, M. Fabiilli, P. Carson and J. Fowlkes, J. Acoust. Soc. Am., 2004, 116, $272-$ 281.

56P. Babiak, A. Němcová, L. Rulíšek and P. Beier, J. Fluor. Chem., 2008, 129, 397-401.

57E. L. Madsen, J. A. Zagzebski and T. Ghilardi-Netto, Med. Phys., 1980, 7, 43-50.

58 S. Inglis, K. Ramnarine, J. Plevris and W. McDicken, Ultrasound Med. Biol., 2006, 32, 249-259.

59 V. Normand, D. L. Lootens, E. Amici, K. P. Plucknett and P. Aymard, Biomacromolecules, 2000, 1, 730-738.

60P. Laugier and G. Haiat, Introduction to the Physics of Ultrasound, 2010.

61 S. A. Sapareto and W. C. Dewey, Int. J. Radiat. Oncol. Biol. Phys., 1984, 10, 787-800.

62P. Zhang, J. A. Kopechek and T. M. Porter, J. Ther. Ultrasound, 2013, 1, 2.

63 W.-S. Chen, C. Lafon, T. J. Matula, S. Vaezy and L. A. Crum, Acoust. Res. Lett. Online, 2003, 4, 41-46.

64 A. H. Lo, O. D. Kripfgans, P. L. Carson and J. B. Fowlkes, Ultrasound Med. Biol, 2006, 32, 95-106.

65 A. Ishijima, J. Tanaka, T. Azuma, K. Minamihata, S. Yamaguchi, E. Kobayashi, T. Nagamune and I. Sakuma, Ultrasonics, 2016, 69, 97-105.

66 V. Auboiroux, L. Petrusca, M. Viallon, A. Muller, S. Terraz, R. Breguet, X. Montet, C. D. Becker and R. Salomir, BioMed Res. Int., 2014, 2014, 9.

67 B. Quesson, C. Laurent, G. Maclair, B. D. de Senneville, C. Mougenot, M. Ries, T.

Carteret, A. Rullier and C. T. W. Moonen, NMR Biomed, 24, 145-153.

68D. Elbes, Q. Denost, C. Laurent, H. Trillaud, A. Rullier and B. Quesson, Ultrasound Med. Biol., 2013, 39, 1388-1397. 
788

789

790

791

792

793

794

795

796

797

798

799

800

801

802

803

804

805

806

807

808

809

810

811

812

813

814

815

816

817

818

819

820

821 


\begin{tabular}{ccccccc} 
Surfactant & $\mathbf{F}_{\mathbf{8}} \mathrm{TAC}_{\mathbf{7}}$ & $\mathbf{F}_{\mathbf{8}} \mathbf{T A C}_{\mathbf{1 3}}$ & $\mathbf{F}_{\mathbf{8}} \mathbf{T A C}_{\mathbf{1 7}}$ & $\mathbf{F}_{\mathbf{6}} \mathbf{T A C}_{\mathbf{7}}$ & $\mathbf{F}_{\mathbf{6}} \mathbf{T A C}_{\mathbf{1 2}}$ & $\mathbf{F}_{\mathbf{6}} \mathbf{T A C}_{\mathbf{2 9}}$ \\
\hline $\mathbf{1 / \mathbf { R } _ { \mathbf { 0 } }}$ & 4 & 8 & 12 & 4 & 12 & 20 \\
Yield & $65.2 \%$ & $84.0 \%$ & $65.1 \%$ & $63.4 \%$ & $81.3 \%$ & $31.8 \%$
\end{tabular}

\begin{tabular}{cccccc} 
& Control & $\mathbf{0 . 1 \%}$ & $\mathbf{0 . 5 \%}$ & $\mathbf{1 \%}$ & $\mathbf{2 \%}$ \\
\hline $\mathrm{H}_{\mathbf{2}} \mathrm{O}^{*}$ & 251.6 & 248.3 & 236.6 & 221.6 & 191.6
\end{tabular}

\begin{tabular}{|c|c|}
\hline emulsion & 0 \\
\hline
\end{tabular}

829

830

831

\begin{tabular}{cccccc} 
& Control & $\mathbf{0 . 1 \%}$ & $\mathbf{0 . 5 \%}$ & $\mathbf{1 \%}$ & $\mathbf{2 \%}$ \\
\hline Volume of $\mathrm{H2O}(\mathrm{mL}) *$ & 251.6 & 248.3 & 236.6 & 221.6 & 191.6 \\
Volume of emulsion $(\mathbf{m L})$ & 0 & 3 & 15 & 30 & 60 \\
$*$ This volume includes the & $50 \mathrm{ml}$ and $5 \mathrm{ml}$ of water added to $\mathrm{SiO}_{2}$ and $\mathrm{BAL}$ respectively
\end{tabular}

Table 2. Volume of water and emulsion added in the TMM gel series (in $\mathrm{mL}$ ).

\begin{tabular}{ccccccc} 
Surfactant & $\mathbf{F}_{\mathbf{8}} \mathrm{TAC}_{\mathbf{7}}$ & $\mathbf{F}_{\mathbf{8}} \mathrm{TAC}_{\mathbf{1 3}}$ & $\mathbf{F}_{\mathbf{8}} \mathrm{TAC}_{\mathbf{1 7}}$ & $\mathbf{F}_{\mathbf{6}} \mathrm{TAC}_{\mathbf{7}}$ & $\mathbf{F}_{\mathbf{6}} \mathrm{TAC}_{\mathbf{1 2}}$ & $\mathbf{F}_{\mathbf{6}} \mathrm{TAC}_{\mathbf{2 9}}$ \\
\hline Size in $\boldsymbol{\mu m}$ & $4.07 \pm 0.12$ & $0.62 \pm 0.02$ & $0.62 \pm 0.09$ & $3.67 \pm 0.17$ & $1.48 \pm 0.22$ & $1.47 \pm 0.09$ \\
PDI $\left(\mathbf{d}_{\mathbf{9 0}} / \mathbf{d}_{\mathbf{1 0}}\right)$ & 4.84 & 3.97 & 3.18 & 4.00 & 2.90 & 2.00
\end{tabular}

Table 3. Droplet's size and polydispersity according the surfactant structure

Difference between $0 \%$ and $0.1 \%$ concentration

\begin{tabular}{llccccccccc}
\hline & $\mathbf{N}$ & $\begin{array}{c}\text { Metric 1 } \\
\left({ }^{\circ} \mathrm{C} / \mathrm{kJ}\right)\end{array}$ & $\begin{array}{c}\text { Precision } \\
\left({ }^{\circ} \mathrm{C} / \mathrm{kJ}\right)\end{array}$ & $\mathbf{P}$ test & $\mathbf{9 5 \%} \mathrm{Cl}$ & $\begin{array}{c}\text { Metric 2 } \\
(\mathrm{J} / \mathbf{k J})\end{array}$ & $\begin{array}{c}\text { Precision } \\
(\mathrm{J} / \mathrm{kJ})\end{array}$ & $\mathbf{P}$ test & $\mathbf{9 5 \%} \mathrm{Cl}$ \\
$\# 1$ & $\mathrm{~F}_{6} \mathrm{TAC}_{7}$ & 4 & 4.30 & 0.39 & $\mathrm{p}<10^{-5}$ & $3.53-5.07$ & 3.56 & 0.44 & $\mathrm{p}<10^{-5}$ & $2.68-4.45$ \\
$\# 2$ & $\mathrm{~F}_{6} \mathrm{TAC}_{7}$ & 5 & 3.45 & 0.22 & $\mathrm{p}<10^{-5}$ & $3.02-3.88$ & 4.03 & 0.32 & $\mathrm{p}<10^{-5}$ & $3.39-4.67$
\end{tabular}

Difference between $0 \%$ and $0.5 \%$ concentration

\begin{tabular}{llccccccccc}
\hline & $\mathbf{N}$ & $\begin{array}{c}\text { Metric 1 } \\
\left({ }^{\circ} \mathrm{C} / \mathbf{k J}\right)\end{array}$ & $\begin{array}{c}\text { Precision } \\
\left({ }^{\circ} \mathrm{C} / \mathrm{kJ}\right)\end{array}$ & $\mathbf{P}$ test & $\mathbf{9 5 \%} \mathrm{Cl}$ & $\begin{array}{c}\text { Metric 2 } \\
(\mathrm{J} / \mathrm{kJ})\end{array}$ & $\begin{array}{c}\text { Precision } \\
(\mathrm{J} / \mathrm{kJ})\end{array}$ & $\mathbf{P}$ test & $\mathbf{9 5 \%} \mathrm{Cl}$ \\
\#1 & $\mathrm{F}_{6} \mathrm{TAC}_{7}$ & 4 & 7.32 & 0.57 & $\mathrm{p}<10^{-5}$ & $6.18-8.47$ & 6.51 & 0.72 & $\mathrm{p}<10^{-5}$ & $5.08-7.95$ \\
$\# 2$ & $\mathrm{~F}_{6} \mathrm{TAC}_{7}$ & 4 & 5.15 & 0.28 & $\mathrm{p}<10^{-5}$ & $4.60-5.70$ & 7.08 & 0.40 & $\mathrm{p}<10^{-5}$ & $6.27-7.88$
\end{tabular}


Difference between $0 \%$ and $0.5 \%$ concentration

\begin{tabular}{|c|c|c|c|c|c|c|c|c|c|c|}
\hline & & $\mathbf{N}$ & $\begin{array}{c}\text { Metric } 1 \\
\left({ }^{\circ} \mathrm{C} / \mathrm{kJ}\right)\end{array}$ & $\begin{array}{c}\text { Precision } \\
\left({ }^{\circ} \mathrm{C} / \mathrm{kJ}\right)\end{array}$ & $P$ test & $95 \% \mathrm{Cl}$ & $\begin{array}{l}\text { Metric } \\
2(\mathrm{~J} / \mathrm{kJ})\end{array}$ & $\begin{array}{c}\text { Precision } \\
(\mathrm{J} / \mathrm{kJ})\end{array}$ & $P$ test & $95 \% \mathrm{Cl}$ \\
\hline \#3 & $F_{6}$ TAC7 & 7 & 4.49 & 0.21 & $p<10^{-5}$ & $4.07-4.91$ & 6.20 & 0.27 & $p<10^{-5}$ & $5.67-6.73$ \\
\hline \#4 & $\mathrm{F}_{6}$ TAC7 & 6 & 3.77 & 0.39 & $p<10^{-5}$ & $2.99-4.54$ & 5.95 & 0.42 & $p<10^{-5}$ & $5.11-6.80$ \\
\hline \#3 & $F_{8}$ TAC7 & 4 & 2.95 & 0.08 & $p<10^{-5}$ & $2.79-3.10$ & 3.93 & 0.14 & $p<10^{-5}$ & $3.65-4.20$ \\
\hline \#4 & $F_{8}$ TAC7 & 4 & 2.90 & 0.17 & $p<10^{-5}$ & $2.57-3.23$ & 4.87 & 0.30 & $p<10^{-5}$ & $4.28-5.47$ \\
\hline
\end{tabular}

845 Table 5. Differential heating factor calculated according to first metrics of MSD absorption effect and integral enhancement of thermal energy absorption by the MSD (second metrics), between $0.0 \%$ and $0.5 \%$ shown for non-absorbent TMM gel series (sample \#3 and \#4). $\mathrm{N}$ stands for the replicates of sonications.

853

854

855

856

857

858

859

860

861

862

863

864

865

866

867

868

869

870
Attenuation of the differential integral enhancement of thermal energy (metric 2) between the first sonication and the second sonication at the same location (first column) and between the first sonication and the third sonication at the same location (second column), measured in non-absorbent gel \#3 and \#4.

\begin{tabular}{ccc}
\hline \#3 Locus A & $0.2 \%$ & $5.2 \%$ \\
\#4 Locus A & $5.0 \%$ & $12.6 \%$ \\
\#4 Locus B & $9.8 \%$ & $12.3 \%$ \\
Average & $5.0 \%$ & $10.0 \%$ \\
ntial integral enhancement of thermal energy (metric 2) be \\
at the same location (first column) and between the first son \\
HIFU cycles & $\mathbf{F}_{\mathbf{6}} \mathbf{T A C}_{\mathbf{7}}$ & $\mathbf{F}_{\mathbf{8}} \mathbf{T A C}_{\mathbf{7}}$ \\
\hline $\mathbf{0}$ & $4.963 \pm 0.465$ & $5.634 \pm 0.273$ \\
$\mathbf{1}$ & $3.132 \pm 0.066$ & $1.434 \pm 0.014$ \\
$\mathbf{2}$ & $2.021 \pm 0.546$ & $1.242 \pm 0.020$ \\
$\mathbf{3}$ & $1.693 \pm 0.016$ & $1.364 \pm 0.110$
\end{tabular}

\section{Sonication 1 vs 2 Sonication 1 vs 3}

Table 7. Effect of HIFU sonication on the MSD average size (units: $\mu \mathrm{m}$ ), performed in a liquid emulsion, for two surfactants. The sonication parameters per cycle pulse duration $=90 \mathrm{~ms}$, duty cycle $=90 \%$, power $=135 \mathrm{~W}$, total duration 33s. 


\section{Figures}

876

877

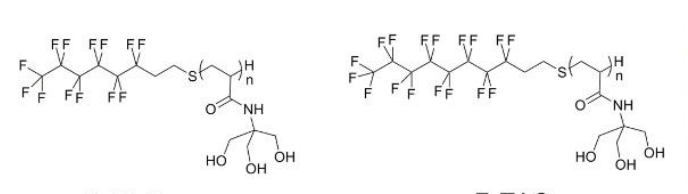

a $\quad \mathrm{F}_{6} \mathrm{TAC}_{\mathrm{n}}$

$\mathrm{F}_{8} \mathrm{TAC}_{\mathrm{n}}$
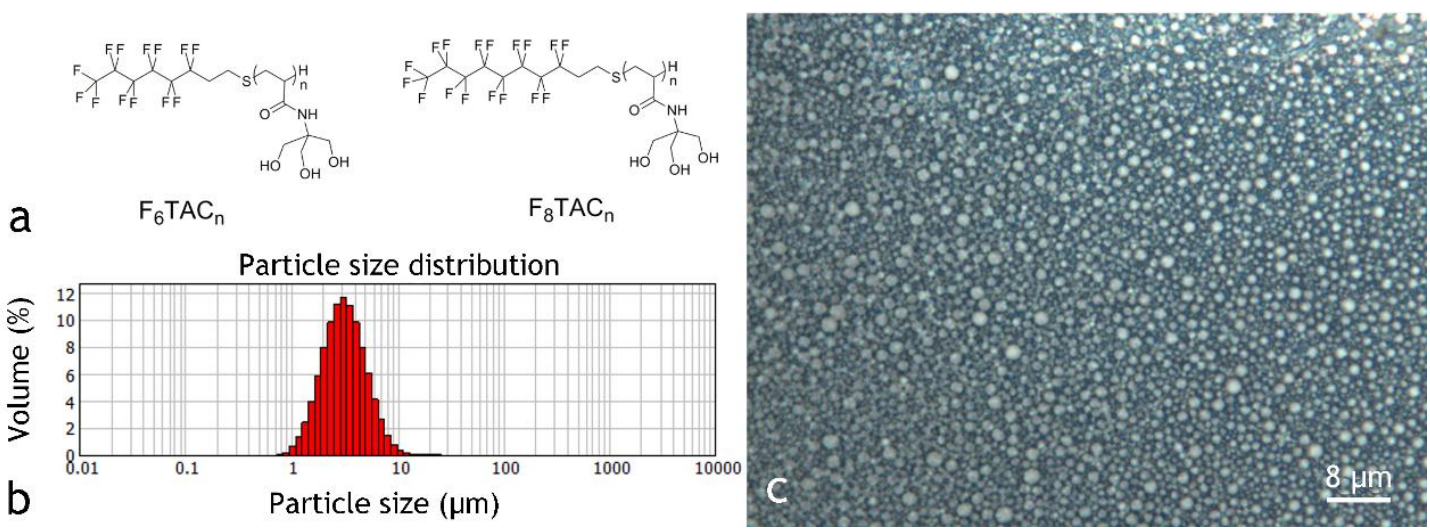

Figure 1 a) Chemical structure of fluorinated surfactant composed of two parts: a hydrophobic carbon chain bearing fluorine and hydrogen atoms $\left(\mathrm{C}_{6} \mathrm{~F}_{13} \mathrm{C}_{2} \mathrm{H}_{4}\right.$ or $\left.\mathrm{C}_{8} \mathrm{~F}_{17} \mathrm{C}_{2} \mathrm{H}_{4}\right)$ and a hydrophilic part made of repeating TRIS units with an average number called DPn (for average degree of polymerisation), b) MSD particle size distribution in volume (Mastersizer 2000) made with $\mathrm{F}_{6} \mathrm{TAC}_{7}$ and c) Optical microscopy of MSD emulsion (x100)
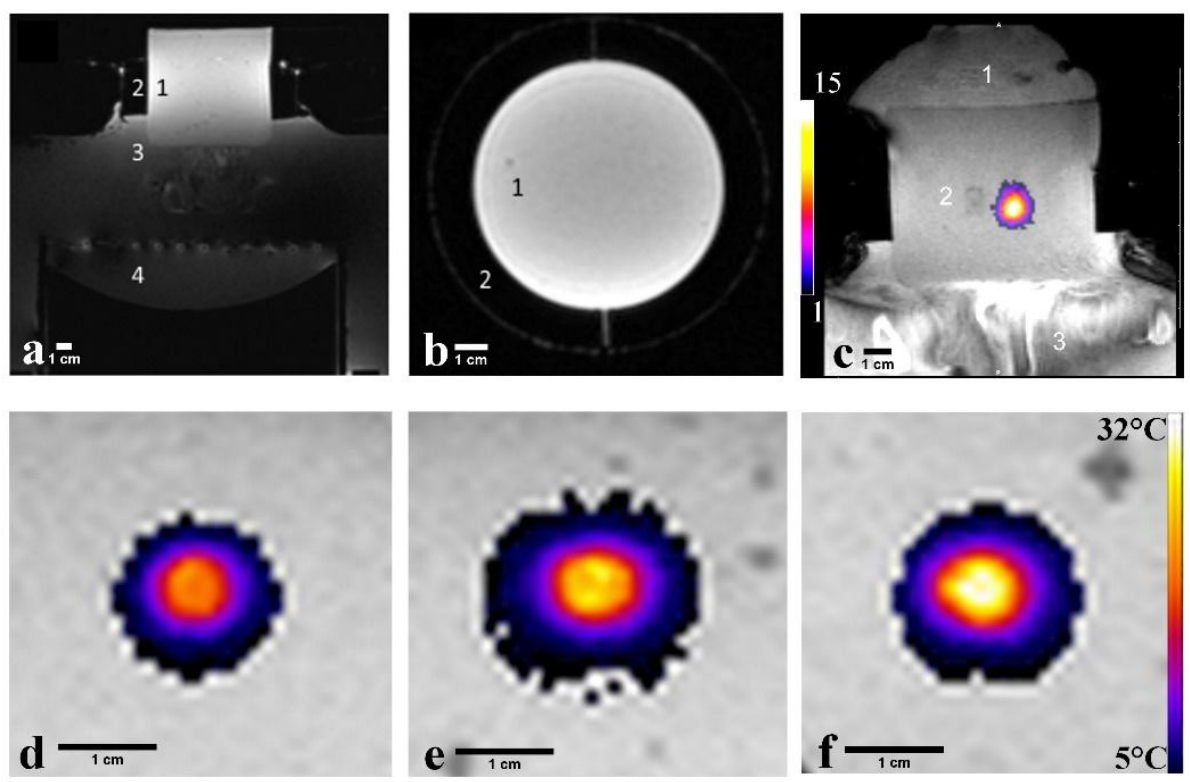

Figure 2. a,b) 3D MR images of the HIFU experimental set up: Transversal (a, FOV $=180 \mathrm{~mm}$ square) 
water, 4 Concave surface of the HIFU applicator, c) Axial view of a magnitude MR image and PRF shift temperature elevation map overlay at the end point of a HIFU exposure in TMM gel loaded with $0.5 \%$ MSD concentration. Temperature elevation color map ranges from $+1^{\circ} \mathrm{C}$ to $+15^{\circ} \mathrm{C}$. Shown FOV is 128 $\mathrm{mm}$ square. Visible is the acoustic streaming in the coupling water layer (3), the TMM gel (2) and the standard ultrasonic gel on the top (1), assuring a non-reflective exit window distal. d,e,f) MR magnitude and overlaid PRF shift temperature elevation map at the end of HIFU exposure interval under identical sonication parameters in three TMM gels with (d) (e) (f); $0 \%, 0.1 \%, 0.5 \%$ MSD concentration respectively. Shown FOV is $30 \mathrm{~mm}$.

897

898
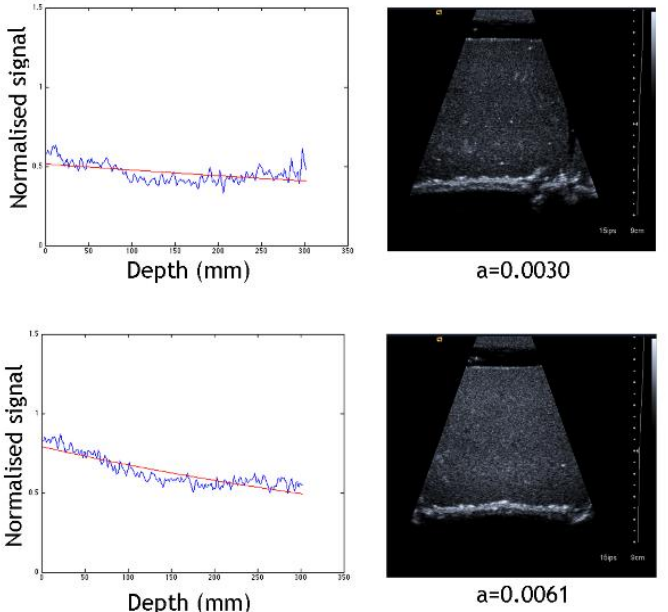

$a=0.0061$

$1 \%$
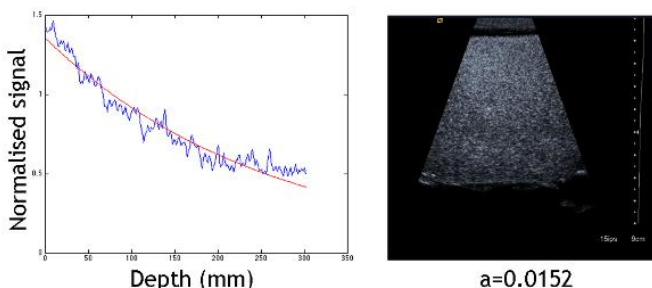

Depth (mm)

$a=0.0152$
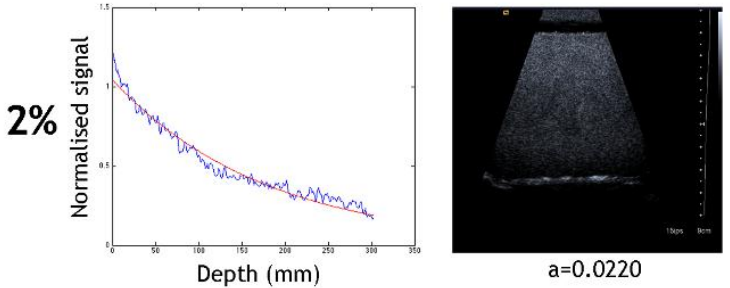

$a=0.0220$

Figure 3. Harmonic ultrasound imaging of loaded MSD gel at $2.2 \mathrm{MHz}$ for the four concentrations provided as embedded text. (Left) The fitted function of the backscattered signal corresponding to a decreasing exponential with the linear attenuation coefficient "a" expressed in units $\mathrm{mm}^{-1}$. Experimental data was taken as the normalized average profile of the US signal intensity in a 150 pixel wide region of interest. (Right) The corresponding native US images. 


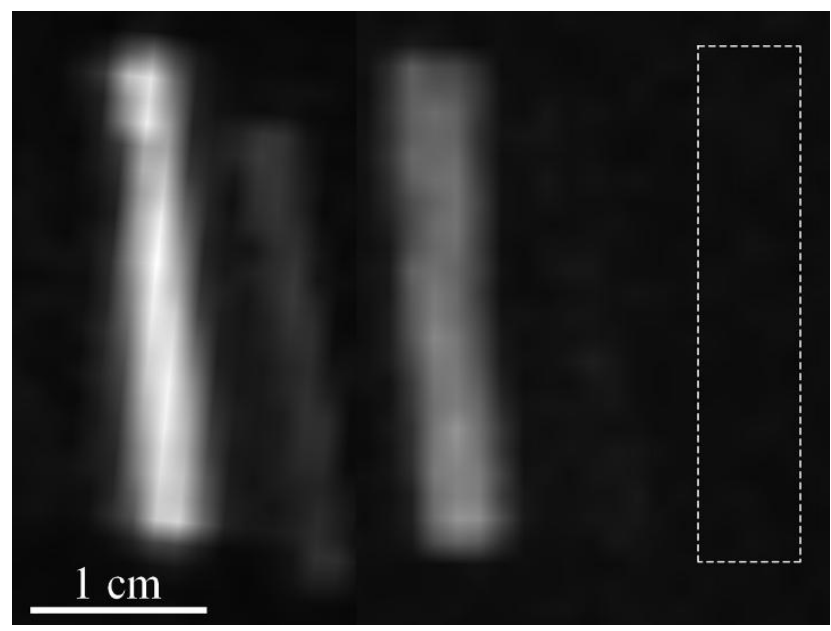

Figure 4. 19F MRI image of sliced gel with different MSD concentration, from left to right : $2 \%, 0.5 \%, 1 \%, 0.1 \%$ and without MSD (overlaid frame in the zero-signal area).
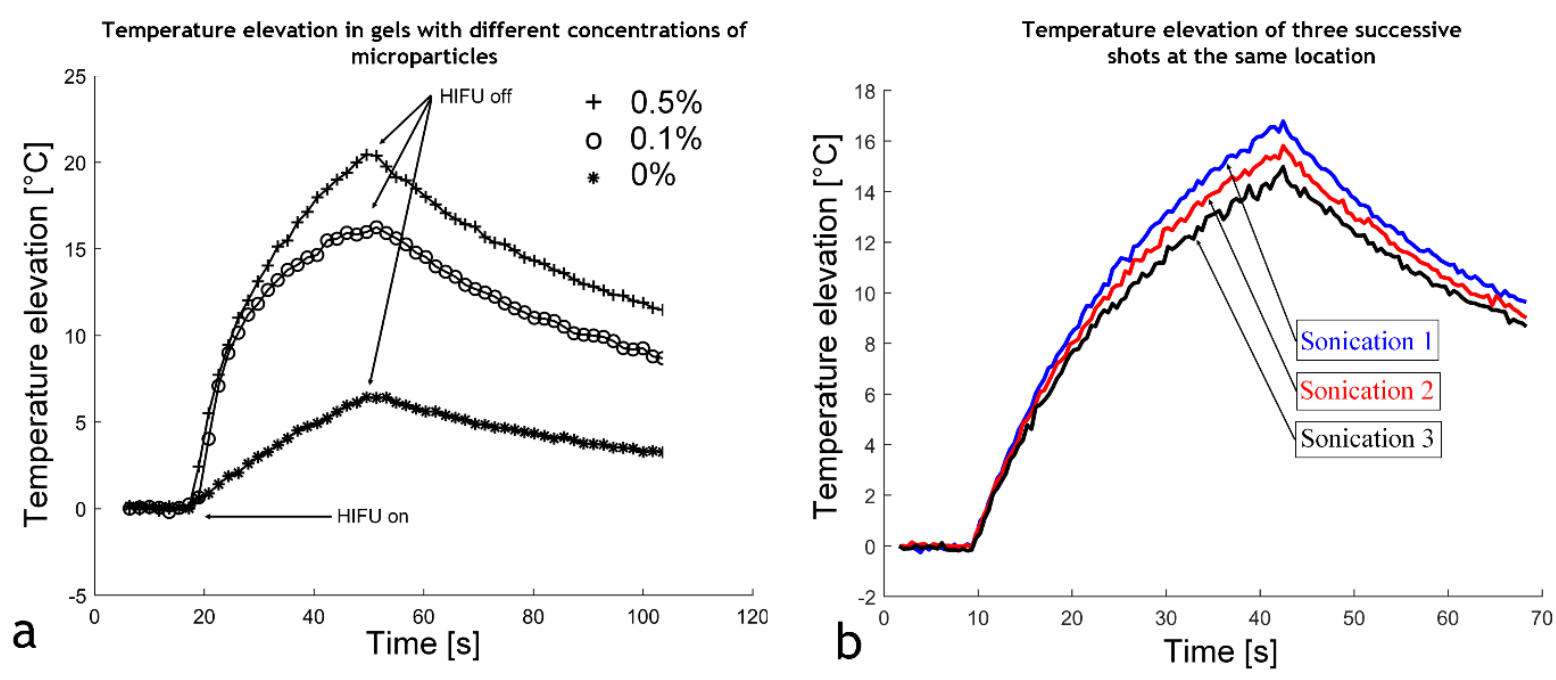

Figure 5. a) Evolution of temperature at the centre of the sonication trajectory in absorbent gels at different MSD concentration (see legend) during HIFU exposure. b) Impact of HIFU repetitions on temperature rising (non-absorbent gel). The same acoustic parameters were applied after 5 minutes delay at the same location. The ulterior sonications gradually induce less thermal effect. The blue line corresponds to the first sonication, the red line corresponds to the second sonication and the black line to the third sonication. 